\title{
Governance and financial efficiency of Brazilian credit unions
}

\author{
Ricardo Terranova Favalli \\ Banco Central do Brasil, Sao Paulo, Brazil, and \\ Alexandre Gori Maia and Jose Maria Ferreira Jardim da Silveira \\ Instituto de Economia, Universidade Estadual de Campinas, Campinas, Brazil
}

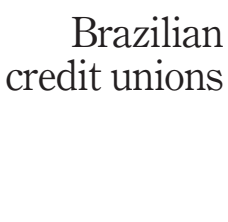

355

Received 8 March 2019 Revised 1 October 2019 Accepted 13 January 2020

\begin{abstract}
Purpose - This paper aims to evaluate the relation between governance and financial efficiency of credit unions in Brazil. The study shows how poor financial efficiency in credit unions may result from undesirable configurations in executive management and other variables related to governance.

Design/methodology/approach - The study develops an innovative methodology to classify credit unions according to the level of governance using indicators of representativeness and participation, leadership, management and supervision. This methodology integrates the use of multiple correspondence and cluster analysis. The study then applies stochastic frontier models to analyze how governance affects the indicators of financial efficiency.

Findings - The results highlight that better governance substantially increases the efficiency of credit unions in terms of a higher level of credit operations per institution.

Originality/value - The paper uses a pioneering survey applied by the Central Bank to almost the total population of credit unions in Brazil. The results highlight how to operationalize a subjective and broad concept related to cooperative governance to identify the remarkable impacts of good governance practices on the financial efficiency of credit unions.
\end{abstract}

Keywords Credit unions, Cluster analysis, Corporate governance, Multiple correspondence analysis, Stochastic frontier model

Paper type Research paper

\section{Introduction}

This study analyzes the financial efficiency of credit unions in Brazil based on their level of governance [1]. The main hypothesis is that an undesirable structure at the executive

(C) Ricardo Terranova Favalli, Alexandre Gori Maia and Jose Maria Ferreira Jardim da Silveira. Published in RAUSP Management Journal. Published by Emerald Publishing Limited. This article is published under the Creative Commons Attribution (CC BY 4.0) license. Anyone may reproduce, distribute, translate and create derivative works of this article (for both commercial and noncommercial purposes), subject to full attribution to the original publication and authors. The full terms of this license may be seen at http://creativecommons.org/licences/by/4.0/legalcode

The authors contributed to the paper in the following ways. Favalli, Ricardo Terranova, Conceptualization (Equal), Formal analysis (Lead), Methodology (Equal), Validation (Lead), Writingoriginal draft (Lead), Writing-review \& editing (Equal), Gori Maia, Alexandre, Corresponding Author, Data curation (Lead), Formal analysis (Equal), Methodology (Lead), Writing-original draft (Equal), Writing-review \& editing (Equal), Silveira, Jose Maria Ferreira Jardim, Conceptualization (Lead), Methodology (Equal), Writing-original draft (Equal), Writing-review \& editing (Equal).

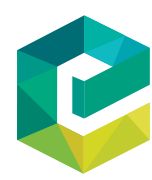

RAUSP Management Journal Vol. 55 No. 3,2020 pp. $355-373$

Emerald Publishing Limited 2531-0488 
RAUSP

55,3

management level and in other variables related to governance would result in poor financial performance. Although the objective of the institution is not to generate profit, given that it must operate at or obtain results that mirror financial equilibrium, it can be assumed that they do not operate at full capacity in terms of credit operations. This negative performance can be evaluated according to variables related to the leverage ratio by observing the fundamental financial activity of these institutions: credit supply.

Credit unions play an important socio-economic role in the Brazilian financial system, usually providing individual financial loans at lower interest rates when compared to traditional bank institutions (Ferreira, Gonçalves, \& Braga, 2007). The supply of credit is based on collective savings and reaches a public that would otherwise be excluded from the financial market due to a lack of collateral. Nonetheless, credit unions operate in a highly competitive and dynamic sector and must continuously adapt to survive in a market that tends toward concentration. At the same time, these institutions need to present financial results that justify their social role (Da Silva, Leite, Guse, \& Gollo, 2017). In such a competitive environment, credit unions need to operate efficiently, which means maximizing results, reducing costs and increasing economies of scale (Da Silva et al., 2017).

For cooperatives that are not able to operate efficiently, the only alternative to avoid liquidation may be to join a larger and more efficient cooperative. The sector witnessed a huge concentration in the last decade. The number of credit unions in Brazil grew substantially in the 1990s and 2000s, reaching 1,461 cooperatives in 2007 (Pinheiro, 2008). Since then, the number of credit unions has declined continuously, reaching 925 cooperatives in 2018 (Banco Central do Brasil, 2018). Meanwhile, the number of cooperative members has steadily grown, reaching 10 million in 2018, compared to 3.5 million in 2008 (Paiva \& Santos, 2017).

Studies on the performance of cooperatives - including credit unions - in Brazil highlight the low efficiency and the importance of the volume of resources on their financial performance (Bressan, Braga, \& Bressan, 2010a; Ferreira et al., 2007; Vilela, Nagano, \& Merlo, 2007). A difficulty inherent in these evaluations is the use of appropriate indicators to measure the financial performance of credit unions, given that profit-making is not an objective of these institutions. Bressan, Braga, Bressan, and Resende Filho (2010b) proposed new indicators to analyze risk management, the creation of ratings and the insolvency of credit unions in Brazil. Barroso (2009) also analyzed the distribution of surplus funds among members, suggesting that the pattern of distribution is directly associated with the cooperative's stage of development.

The level of governance may also be fundamental to the financial performance of the institutions. According to Silveira, Perobelli, and Barros (2008), the level of financial leverage of companies is directly related to their governance practices; more specifically, regarding the access to information and the quality of its content, the structure of the advisory board and ownership structure. Bertucci, Bernardes, and Brandão (2006) also highlight the low level of governance in companies in Brazil, which is largely associated with the low level of protection of minority investors. According to Almeida, Santos, Ferreira, and Torres (2010), the composition and functioning of the advisory board are the main problems in Brazilian companies, given that very few have external and independent advisors.

This study analyzes the relation between governance and the financial efficiency of credit unions, making two principal contributions to the literature. First, it presents a new methodology to typify and analyze the cooperatives' performance and organizational structure: their level of cooperative governance. Second, it explores the use of stochastic frontier models to evaluate how "cooperative governance" affects the efficiency of credit 
unions. The analyses highlight innovative information obtained from surveys conducted by the Central Bank of Brazil on Brazilian credit unions and on their annual reports taken from the Accounting Plan of the National Financial System Institutions (COSIF), also compiled by the Central Bank (Banco Central do Brasil, 2009).

The study provides a better understanding of the relation between the size of cooperatives and attributes associated with the level of personal interference on their decision processes. The results confirm the positive impact of cooperative governance on the cooperatives' financial performance. The study also provides elements for further regional analysis, indicating the positive results for cooperative governance and the financial performance in the south region of Brazil, which opens up a path for new investigations on the link between social capital and cooperativism.

\section{Literature review}

\subsection{Technical efficiency of credit unions}

Few studies have evaluated the relationship between governance and the financial performance of credit unions. Studies evaluating the financial efficiency of credit unions are more common. Ferreira et al. (2007), for example, investigated the performance of financial cooperatives and mutual organizations in the state of Minas Gerais based on the concept of efficiency in the institutions' activities. Their sample contained 105 institutions and used data envelopment analysis (DEA) with product orientation. The model developed by Ferreira et al. (2007) was based on two concepts of efficiency: technique and scale. The most relevant determinants of efficiency identified by the authors were capitalization, working capital, leverage and profit generation.

Da Silva et al. (2017) also applied DEA to analyze the economic and financial performance of the largest credit unions in Brazil. The authors highlighted that the capacity for growth in loan activity to cooperative members is positively related to both the rates of economic and financial performance and the loan capacity dispensed to its members. The authors then emphasize that increases in the financial and economic performance would provide a relative advantage for credit unions by increasing the availability of resources within the cooperative and the ability to provide loans to the associate members.

Carvalho, Diaz, Bialoskorski Neto, and Kalatzis (2015) highlighted how size and management practices might affect the survival and longevity of credit unions in Brazil. The size, proxied by total assets, showed to be strongly associated with lifespan. Funding and investment management also showed to be more important than traditional indicators of financial efficiencies, such as banking profitability, return on assets and credit profitability, in determining longevity and risk of market exit. According to the authors, credit unions must conciliate cooperative principles and requirements imposed by the market and competition, and a higher level of activity and loyalty among members may be a key factor in determining better benefits and, therefore, lower profitability.

International studies also highlighted the importance of size and financial risk on the efficiency of credit unions. Martínez-Campillo, Fernández-Santos, and Sierra-Fernández (2017) analyzed the factors that may have affected the technical efficiency of Spanish credit unions during the 2008 financial crisis. The study highlighted that the most efficient credit unions are those with a greater proportion of branches concentrated in urban centers; are larger; and are less capitalized and therefore face a lower financial risk. The study also emphasized the difficulty in quantifying the indicators of financial performance and the lack of indicators that measure the quality and other qualitative aspects of credit union banking activity. 
RAUSP

55,3

\subsection{Governance of credit unions}

The literature has also focused on methodologies to measure governance and management practices, as these variables tend to be associated with financial efficiency. For example, Barroso (2009) developed a methodology to typify credit unions according to the distribution of their surplus funds: via deposit into the member's account; as an additional share of the entity's capital stock; and via the distribution of surplus of statutory reserves or "indivisible" provisions. Based on a sample of just seven rural credit unions, the author identified "trapping" mechanisms, which can be applied by the cooperative's executive management to members. These mechanisms take place via the distribution of capital stock, or non-distribution to generate reserves and provisions, resulting in the institution retaining, at least temporarily, resources that the members have the right to receive.

On the one hand, the author did not detect a significant relationship between the type of cooperative and return on equity, suggesting, therefore, no relation between financial performance and the type of distribution of net surplus predominant in the institution. On the other hand, the size of the institution determined how surplus was distributed: the larger ones making the majority of payments via bank deposits; and the smaller cooperatives striving for growth and increased patrimony, and retaining a large amount of resources via capital shares, or directly to its equity.

Bressan, Braga, Bressan, and Resende-Filho (2012) explored the security controls used by credit unions on "member-customers" in the form of "security deposits." Security deposits, also known as a "credit guarantee fund," represent a safeguard for financial institutions and their members. Using the principal-agent (P-A) approach, the authors detected the existence of moral hazard when the board of directors and/or managers (A) are likely to disregard the potential risk of insolvency: they are aware that the deposits can be covered by insurance administrated by an external entity $(\mathrm{P})$.

Krieg (2003) analyzed the inducing factors of cooperative governance in American credit unions. The author characterized three main categories of policy control: cooperatives managed by "sponsors"; self-administered, considering a dominance of members that lend or borrow money [2]; and those lead by market control when there is external competition for the financial resources and services provided by the credit unions. The study concluded that "spreads" (in this case, the difference in rates on loans and deposits) were related to the type of control agent in the credit unions.

A more recent and growing area of literature has focused on the role of governance on credit unions' performance, such as the effects of the board's members and membership involvement (Maia et al., 2019). In Canada, Guerrero, Lapalme, Herrbach, and Séguin (2017) identified a positive relationship between the effectiveness of credit union boards of directors at fulfilling the oversight role (monitoring function) and their level of conscientiousness and identification with shareholders. Jones and Kalmi (2015) highlighted a positive relation between membership rate, given by the ratio of members' overall customers [3] and the performance of financial cooperatives in Finland. McKillop and Wilson (2015) highlighted that a sustainable growth of a credit union would require an appropriate and adaptive regulatory and supervisory framework. According to the authors, effective credit union governance also depends on the willingness of members to exercise their rights of ownership, expressing their views to the board of directors and holding them accountable for the performance of the credit union.

The main difference of our study compared to these prior studies regarding the governance and management of credit unions refers to the broader definition of governance. We used data from a survey that explored the most varied components of the concept of internal governance, obtained from data supplied by Brazilian credit unions. It is possible to 
detect some similarities between the methodology employed in this analysis and that adopted by Khiari, Karaa, and Omri (2007). These authors used some governance indicators obtained from the "code of good practice," to determine a sound level of "good governance." They analyzed a sample of 320 American companies listed on the stock market and used factor analysis to select the most relevant unobserved variables. The stochastic frontier analysis was used to estimate the effect of unobserved variables of governance on the financial performance of these companies.

The literature cited often uses profit generation to measure the ability to generate a surplus, which is a characteristic of credit union efficiency. Our study avoids the direct approach of profit generation as an isolated proxy of efficiency, choosing to use an indicator of financial performance related to the return on equity and disregarding the cases with no positive returns. The objective is to show that administrative failures can result in unsatisfactory economic performance, instead of testing if the distribution of surplus behaves differently in non-profit organizations in comparison to what the theory predicts in the case of profit-led firms.

\section{Material and methods}

Information obtained from the cooperative governance survey, conducted by the Brazilian Central Bank (BACEN) in the second half of 2007, was combined with data on public accounts, extracted from the COSIF 4010/4016 and also compiled by the BACEN. The final sample contained information from 1,199 cooperatives. The data were an obligatory requirement of the regulatory body and made up observations obtained from $86 \%$ of the credit unions active in the Brazilian economy at the time.

The cooperative governance survey carried out in 2007 marked an important time for the sector in Brazil. First, it marks the period when the number of cooperatives reached a historical peak (Banco Central do Brasil, 2018). Since then, the number of credit unions has decreased as a result of the concentration in the sector. Second, because this survey was carried out soon after the establishment of a special unit in the BACEN to work with the supervision of cooperatives (in 2005), which has since then applied a wide-range of supervisory activities aiming to promote good practices of governance and management. Thus, this data set provides a unique source of information to analyze aspects of governance that may be related to financial efficiency and, most likely, to the survival of credit unions.

The questions in the cooperative governance survey were subdivided into three principal sections:

(1) representativeness and participation (RP), with 30 variables;

(2) strategic leadership (LS), with 17 variables; and

(3) management and supervision (MS), with 23 variables.

Each categorical variable presented two or more categories, which resulted in a total of 229 categories of analysis. This study will only highlight the most relevant categories to understand the differences between the dimensions and groups of analysis. A complete description of the questionnaire and response categories can be found in Banco Central do Brasil (2009, pp. 191-240).

The structure of associations between the cooperatives and the multiple qualitative response categories of the cooperative governance survey was obtained by using multivariate analysis techniques. First, we used multiple correspondence analysis (MCA) to reduce the dimensionality of the associations between the multiple qualitative response categories. Next, we used cluster analysis (CA) to define groups of credit unions (governance 
RAUSP

55,3

groups) in such a way that the patterns of association among the response categories were homogeneous within and heterogeneous between the groups.

The association between the governance groups and the financial indicators was then analyzed using descriptive analyses and stochastic frontier (SF) models. The SF models allowed us to estimate both the determinants of the financial performance (production function) and the technical efficiency of the governance groups.

\subsection{Multiple correspondence analysis}

MCA is an extension of correspondence analysis, which allows one to analyze the pattern of association of several categorical variables. Based on a contingency table with multiple combinations of qualitative categories, MCA eliminates the use of redundant information and determines the number of relevant dimensions that must be considered to understand the structure of associations in the response categories (Greenacre, 1984). MCA is based on the technique of principal components: a reduced number of dimensions is obtained to explain a greater proportion of the information presented in the data (Cuadras, 1981). After identifying the principal dimensions (components) that better represent the data structure, MCA simplifies the understanding of the structure of associations of the response categories.

The MCA uses singular value decomposition to decompose the basic structure of a matrix into eigenvalues and eigenvectors. The technique decomposes the differences between the categories of interest (distances $\chi^{2}$ ) into:

- eigenvalues that represent the partial contributions of each dimension to explain the total variability of the data; and

- eigenvectors that represent geometric projection plans (Greenacre \& Hastie, 1987).

Each eigenvalue represents the relative importance of its respective dimension and how much of the total inertia (variance or dispersion) it explains. The total inertia corresponds to the average differences (distances) between the multiple combinations of frequencies and the average frequency of the population (average profile).

The geometric dispersion of the categories in the space defined by the dimensions of MCA describes the patterns of association between the qualitative variables. Groups of categories close to one another present similar patterns of relationship (Hoffman \& Franke, 1986). In turn, the closer the response category's vector location is to the origin; the more similar the category is to the average profile.

\subsection{Cluster analysis}

The main dimensions resultant from MCA were used in CA to classify the credit unions and the response categories into relatively homogeneous groups of cooperative governance. Cluster analysis defines hierarchical groups of observations within a population. A series of methods can be employed in this process, all of which are based on the same principle of hierarchical grouping. At the beginning of the process, each element represents a cluster. The two closest clusters are united to form a new cluster that substitutes them. This pattern follows until there is only one left. The way to calculate the distance (or dissimilarity) between clusters differentiates the available methodologies.

Our study adopted Ward's grouping method, an aggregation strategy based on the analysis of variances within and between the groups. The objective of Ward's method is to create hierarchical groups in such a way that the variances within the groups are minimized and the variances between the groups are maximized (Crivisqui, 1999). The aggregation 
criteria of each stage of the technique consists of finding the next class that minimizes the variability within a new group. To understand the sums of the squares within the groups, they tend to be divided by the total sum of the squares (total variability) to represent a share of maximum variability $\left(R^{2}\right.$ semi-partial).

At the beginning of the process, the degree of generalization is zero (all the observations are distinct from each other), and at the end of the process, we have $100 \%$ generalization (all observations are similar to one another). The researcher must define the number of groups to be used in the research considering the degree of generalization that will be adopted. In this respect, we took into consideration both criteria, analyzing the losses and gains of each one.

\subsection{Stochastic frontier model}

The SF models were initially developed by Aigner, Lovell, and Schmidt (1977) and Meeusen and Van Den Broeck (1977) to estimate the inefficiency associated with a traditional function of production (or cost). In other words, when $y i$ is the production (or cost) of company $i$ (output) and $\mathbf{x}_{\boldsymbol{i}}$ a vector of $k$ explanatory factors (inputs), the function of production or costs would be given by:

$$
\ln y_{i}=\mathbf{x}_{i} \beta+e_{i} \quad i=1, . ., n
$$

The SF model allows us to disaggregate the error $e_{i}$ into two specific components:

(1) aleatory shocks $\left(v_{i}\right)$, resultant, for example, from an unexpected or unobserved factor; and

(2) components associated with technological inefficiency $\left(u_{i}\right)$.

In other words:

$$
\ln y_{i}=\mathbf{x}_{i} \beta+v_{i}-u_{i}
$$

The shock $v_{i}$ is assumed to be independent and identically distributed, and independent of $u_{i}$. In the case of a production function, $u_{i}$ is positive and represents technological inefficiency. In other words, $u_{i}$ represents a factor which contributes to the firm's inability to attain the maximum feasible production. In the case of a cost function, $u_{i}$ is negative and represents the inefficiency of cost, i.e. a factor the contributes to the inability to attain the minimum feasible cost. The functions usually used to represent the probability density of $u_{i}$ are half normal, truncated normal, exponential or gamma (Coelli, Rao, \& Battese, 1998).

An extension of the SF model consists of predicting the component associated with inefficiency $\left(u_{i}\right)$ as a function of a vector $\mathbf{z}_{i}$ of the characteristics, such as administrative experience or cooperative governance (Battese \& Coelli, 1995). In other words, we will have:

$$
\begin{gathered}
v_{i} \sim N\left(0, \sigma_{v}^{2}\right) \\
u_{i} \sim N^{+}\left(\mu_{i}, \sigma_{u}^{2}\right) \\
\mu_{i}=\mathbf{z}_{i} \delta
\end{gathered}
$$

In this case, $u_{i}$ presents normal positive distribution with an average value $\mu_{i}$ conditional to the characteristics $\mathbf{z}_{i}$, and $\delta$ is a vector of coefficients to be estimated. The estimation 
RAUSP

55,3

\section{2}

strategy consists of maximizing the function of $\log$-likelihood conditioned to the vector of coefficients $\boldsymbol{\beta}$ and $\boldsymbol{\delta}$, and to the parameters $\sigma^{2}=\sigma_{v}^{2}+\sigma_{u}^{2}$ and $\gamma=\sigma_{u}^{2} /\left(\sigma_{v}^{2}+\sigma_{u}^{2}\right)$ (Battese $\&$ Coelli, 1995).

In addition to defining the determinants of production and efficiency, a particularly useful analysis using the SF model is the estimation of technical efficiency. Based on equation (2), the production (or cost) $y_{i}$ can be given by the product of three components:

$$
y_{i}=\exp \left(\mathbf{x}_{i} \beta\right) \times \exp \left(v_{i}\right) \times \exp \left(-u_{i}\right)
$$

The product of the first two components $-\exp \left(\mathbf{x}_{i} \beta\right) \times \exp \left(v_{i}\right)$ - defines the production possibility frontier, i.e. the level of production considering a hypothesis of total productive efficiency. In turn, the inefficiency component $\exp \left(-u_{i}\right)$ represents the distance to the production possibility frontier as a result of inefficiency. Based on this analysis, we can extract one of the most common measures of technical efficiency, $T E_{i}$ (Coelli et al., 1998):

$$
T E_{i}=\frac{y_{i}}{\exp \left(\mathbf{x}_{i} \beta\right) \times \exp \left(v_{i}\right)}=\exp \left(-u_{i}\right)
$$

In the case of a production function, $T E_{i}$ assumes a value between 0 and 1 , which represents the ratio between the observed production for $i$ and its maximum expected production. In other words, $T E_{i}$ represents the share of the maximum production attained by $i$. In the case of a cost function, the value of $T E_{i}$ is between 1 and infinity and represents the ratio between the observed cost and the minimum cost. Thus, the closer $T E_{i}$ is to 1 , in both situations, the closer $i$ is to total efficiency.

\section{Results}

\subsection{Cooperative governance}

The MCA was applied independently to each section of the cooperative governance questionnaire (RP, LS and MS). Null answers were treated as an additional response category, as these situations may also highlight a situation of low governance. For example, answers could be null because the person responsible for filling out the questionnaire lacked adequate technical knowledge or because the mechanism under evaluation was inexistent in the cooperative. The cooperatives with a high number of null answers were excluded so that the multivariate analysis would not be too heavily influenced by extreme values [4].

We selected the main dimension of MCA of each section to represent the multiple relationships between the cooperatives and the qualitative categories in the respective section of the questionnaire. The principal dimension of $\mathrm{RP}$ represented $6.7 \%$ of the total variability (inertia) of the information; the principal dimension of DI represented $8.6 \%$ of the total variability, and the principal dimension of MS represented $8.1 \%$ of total variability.

Even though the contribution of one dimension alone to explain the patterns of the relationship of a section may initially seem low, the multiplicity of variables and situations defined by the categories of analysis must be considered. Thus, one variable alone that represents, for example, $7 \%$ of the totality of associations of the RP section, cannot be considered as having low discriminatory power. Furthermore, the decision to represent the most important dimensions when defining governance patterns prevents the subsequent classification of cooperatives by cluster analysis from generating overly heterogeneous groups, with no evident pattern of defining the most relevant variables in the questionnaire. below:

The principal dimension of each section obtained from the MCA is briefly described 
- Representativeness and participation (RP): dimension positively associated with the high participation of members in the meetings prior to Annual General Meetings (AGM), the realization of periodic and systematic meetings with members, the existence of a specific project to form new leaders among the members and the realization of educational programs on cooperative/finance. This dimension was negatively associated with the absence of measures to stimulate the participation of members in the meetings and with members that use the cooperative like any other financial institution. In other words, the greater the value of this dimension, the better the level of governance related to the representativeness and to the participation of the members at the governance and management levels - including in meetings - given the greater commitment and inclusion of members in decisionmaking and positive actions of the cooperative in terms of educational programs and member training.

- Leadership (LS): dimension positively associated with the absence of an Advisory Board $(\mathrm{AB})$ and to the answers considered qualitatively negative, or not answered, in relation, for example, to the adequate conduction of administrative issues by the director or executive, to the method of remuneration of members of the $A B / B$ oard of Directors and to the function of executive director accountability regarding control bodies and internal control (such as the AB and Fiscal Advice). This dimension is negatively associated with the existence of formal mechanisms to evaluate the $\mathrm{AB}$ and/or director-president. Thus, the greater the value of this dimension, the greater the association between the cooperative and the inadequacy of structures verified by the section of the questionnaire referring to leadership (strategy - primarily related to the effectiveness of the Advisory Board). The lower the value of this dimension, the greater the cooperative's commitment to periodic evaluations of the Advisory Board and/or director-president.

- Management and supervision (MS): dimension positively associated with the existence of better management remuneration structures related to gains in: number of members; capital stock, equity or deposits [5]; the existence of internal audits; and null answers in relation to members' motivation to participate in the $A B$ and encouragement to apply to be on the AB. This dimension is negatively associated with a lack of specific training for fiscal advisors, the inexistence of a regular process to make new advisors aware of cooperative activities and a lack of planning with defined objectives. Therefore, the greater the value of this dimension, the better the results regarding the cooperative's mechanisms of remuneration, planning and effectiveness of actions carried out by $\mathrm{AB}$ members, the adequateness of internal audit structures and other forms of supervising administrative actions. On the other hand, low values of this dimension are associated with the absence of administrative management and planning mechanisms, a lack of training, planning and other aspects to induce effective $\mathrm{AB}$ activities.

The three principal dimensions of MCA were used as grouping criteria by $\mathrm{CA}$, adopting Ward's minimum variance method. We used two measures to validate the clustering structure (internal validation): $R^{2}$ and semi-partial $R^{2}$. The $R^{2}$ measures the extent to which the groups are different from each other: the higher the $R^{2}$, the higher the proportion of the total variability (joint variance of three principal dimensions of MCA) explained by the clusters. The semi-partial $R^{2}$ measures how similar the cluster elements are to each other: the lower the semi-partial $R^{2}$, the more homogeneous the cluster elements are. 
RAUSP

55,3

\section{4}

Figure 1.

Dispersion of cooperatives according to MCA dimensions and $\mathrm{AC}$ classification

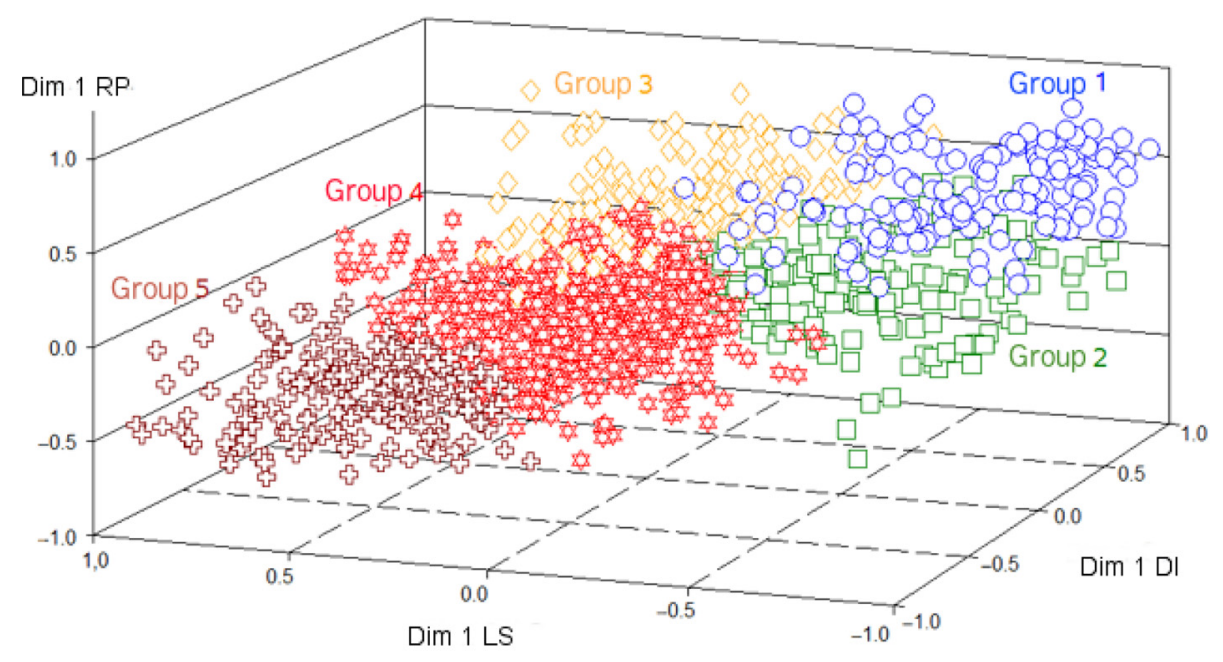

Source: Research data

Based on the measures of internal validation and the analytical limitation imposed by the cluster structure, we selected five groups of cooperative governance. The cluster presented a reasonable explanatory power: the average differences between the selected groups represented approximately $69 \%$ of the total variability of the three dimensions $\left(R^{2}\right)$. Moreover, the cluster elements are equal to each other: semi-partial $R^{2}$ equals $2.8 \%$, i.e. the inclusion of an additional cluster would add little information to explain the total variability.

Figure 1 shows the dispersion of cooperatives in the space defined by the three dimensions of the MCA, presented in Figure 1. Although CA does not allow us to establish a scale of differences between the selected groups, we defined a hierarchy based on the average variable values of each dimension:

- Group 1 (C1) - High-High-High Governance (147 institutions, $12.4 \%$ of the total): the cooperatives in this group tend to represent the best results in the three sections, i.e. a relatively high level of governance in RP, LS and MS.

- Group 2 (C2) - Medium-High-High Governance (157 institutions, 13.3\%): cooperatives with a good performance in LS and MS, inferior only to Group 1. This group, however, presents moderate results of $\mathrm{RP}$, which are inferior to those in Group 3.

- Group 3 (C3) - High-Medium-Medium Governance (147 institutions, 12.4\%): cooperatives with a good performance in RP (only inferior to group 1), moderate performance in DI and MS, inferior to those in Group 2.

- Group 4 (C4) - Medium-Medium-Low Governance (523 institutions, 44.2\%): the most expressive group, concentrating cooperatives that present a low performance in MS and relatively moderate performance in RP and LS. These results are only higher than those of Group 5.

- Group 5 (C5) - Low-Low-Low Governance (210 institutions, 17.7\%): cooperatives that tend to present the worst levels in the three sections. 
Some positive characteristics that qualify the groups with high levels of governance were also found in intermediary groups. In general, the first three (the best) groups of cooperative governance (38\% of cooperatives) presented relatively high levels of governance, while the bottom two (the worst) groups (62\% of cooperatives) presented moderate or low levels of governance.

A more detailed description of the groups was obtained from the original variables presented in the questionnaire. Groups 1 and 3 were considered more advanced in RP, with greater member participation. The main characteristics that distinguished these groups were: the implementation of actions to encourage members to participate in general meetings; meetings prior to the AGM and other types of meetings with members; member access to channels of information and communication to make their participation viable, and the predominance of institutions with educational programs on cooperatives, finance and the formation of future leaders.

The cooperatives in Groups 2 and 4 presented moderate performances in RP. The second group presented some better results, such as a greater presence of formal measures to restrict members in political-partisan posts. Among the characteristics that were similar in both Groups 2 and 4, it is worth mentioning: the majority of institutions take some form of action to encourage members to take part in general meetings, and approximately $40 \%$ of participants in the groups mentioned the existence of electoral committees to choose executive managers in AGMs.

Group 5 presented the worst performance in RP: negative characteristics associated to the lack of actions taken to increase member participation in general meetings; the nondisclosure, prior to meetings, of the names and elective posts of the candidates; and the nondisclosure, in the majority of institutions, of any educational programs related to cooperatives, finance and the formation of leaders.

The best performances in LS were observed in the cooperatives in Groups 1 and 2. The first group stood out due to the greater presence of regulations regarding reelection. The principal characteristics that distinguish Groups 1 and 2 from the others were: the predominance of regulation on transactions with related parties [6]; and control over the hiring of supervisors and managers. Groups 3 and 4 showed moderate performances in LS. The third group presented a relatively superior performance, for example, in terms of the regulation of statutory body actions. Some characteristics that distinguished Groups 3 and 4 are: the existence of criteria to define director remuneration [7]; relatively high participation (around 35\%) of operations with members of the board of directors; and the existence of procedures to pass the information on to new administrators. Group 5 stood out for its negative performance that denotes low levels of governance in LS, such as lack of regulatory actions on operations with the board of directors; no follow-up on actions taken by executive management and managers; and the absence of procedures to pass on information to new administrators, in approximately half of the group.

The cooperatives in Groups 1 and 2 presented better performances in MS, differing from the others with more adequate levels of internal control and managing credit operations; and better conditions in which the role of fiscal advisor can be exercised. Group 3 presented moderate performance in MS, contrary to the groups with poorer performance (4 and 5) in terms of the following characteristics: the existence of reports specifically for members; training for fiscal advisors; and planned participation of substitutes in $\mathrm{AB}$ meetings. Group 4 registered slightly higher levels of MS than Group 5, in terms of the existence of planning with outlined targets and a code of ethics. The unsatisfactory performance of these two groups was also seen in the absence of programs associated with social and/or 
RAUSP

55,3

Table 1.

Percentages and average values of diverse characteristics according to cooperative governance groups (values in parentheses represent the results of the statistical tests) environmental responsibility; the lack of participation from substitutes in AB meetings; and inadequate internal control structures and procedures related to managing credit operations.

\subsection{Financial performance of the governance groups}

Table 1 presents the percentages and average values of selected socioeconomic indicators. The distribution of the groups across the five Brazilian regions confirms expectations concerning regional differences in the models of Brazilian credit unions. The best results were seen in the Southern region, with the largest share of cooperatives in the groups qualified as having relatively higher levels of governance (64\% of cooperatives in Groups 1 , 2 and 3). The institutions in the Central-West region presented, on average, better performances than the other regions, with the exception of the Southern region.

The number of members is a proxy for economic and financial capital. In spite of the aim to preserve the cooperative and equitable relation terms, cooperatives must reach the largest public possible to remain competitive on the financial market. Even though there is no clearcut hierarchy between the groups, there is a well-defined pattern of differences between the average number of members in cooperatives with high and medium level governance (Groups 1, 2 and 3) and low governance (Groups 4 and 5). For example, the average number of members in Group 1 is more than five times greater than Group 5. Larger credit unions must operate more efficiently, using more adequate governance tools. Also, increases in the membership may result in increasing learning gains in management.

In turn, there was no direct relationship between the number of employees and the level of governance. Larger institutions may present economies of scale vis-à-vis the presence of better governance structures. As a result, the largest institutions have fewer members/ employees than smaller ones. Despite no significant differences between the average numbers of members/employees among the groups, the difference in the cooperatives with low levels of governance stood out. An extreme situation was seen in the group with the

\begin{tabular}{lccccc}
\hline & \multicolumn{5}{c}{ Cluster } \\
Variable & 1 & 2 & 3 & 4 & 5 \\
\hline No. of cooperatives & 112 & 124 & 109 & 391 & 130 \\
Region (Row \%) & & & & & \\
North & 4.7 & 14.0 & 18.6 & 55.8 & 7.0 \\
Northeast & 8.6 & 10.3 & 12.1 & 58.6 & 10.3 \\
Central-west & 14.7 & 26.7 & 16.0 & 34.7 & 8.0 \\
Southeast & 6.6 & 12.6 & 6.6 & 51.3 & 22.9 \\
South & 27.1 & 14.8 & 22.0 & 31.4 & 4.7 \\
& $7,402(\mathrm{~A})$ & $3,765(\mathrm{~B})$ & 4,647 (B) & $2.051(\mathrm{C})$ & $1.354(\mathrm{C})$ \\
No. of members & $41.2(\mathrm{~A})$ & $23.7(\mathrm{AB})$ & $32.0(\mathrm{AB})$ & $16.8(\mathrm{~B})$ & $30.1(\mathrm{AB})$ \\
No. of employees & $185.2(\mathrm{~B})$ & $160.3(\mathrm{~B})$ & $164.1(\mathrm{~B})$ & $217.8(\mathrm{~B})$ & $392.3(\mathrm{~A})$ \\
No. of members/employees & & & &
\end{tabular}

Notes: *** Significance at the $0.1 \%$ level by the test $\chi^{2}$ for the contingency tables, (A) (B) (C) (D) (E): represent the hierarchy of the average values. Averages with the same letter are not significantly different from the significance level of $5 \%$ by the Duncan test

Source: Research data 
lowest level of governance (Group 5), that presented a value more than two times greater than the groups with medium and high levels of governance.

The results presented in Figure 2 provide an initial view of the relationship between the governance groups and cooperative performance. The financial indicator used in this analysis is the leverage ratio: the ratio between the net loans (excluding provision for loan loss) and the institution's equity [8]. Higher leverage is expected to represent better financial performance. The cooperatives in the groups with the highest levels of governance presented the best performances, meaning a higher concentration of values of leverage ratio on the right side of the distribution. Cooperatives in $\mathrm{C} 1$ presented the highest leverages. The result does not eliminate, however, the occurrence of low leverage in cooperatives of this same group, that occurs at a lower rate than in the other groups. Cooperatives in $\mathrm{C} 3$ presented a similar performance to $\mathrm{C} 1$, with close modal values and lower dispersion of leverages in the inferior and superior extremes. Also, with a similar performance, the cooperatives in $\mathrm{C} 2$ stood out with greater dispersion of leverages and concentration of values inferior to those in groups $\mathrm{C} 1$ and $\mathrm{C} 3$.

Groups C4 and C5 presented performance levels inferior to the others, with high frequencies of low leverages, above all for the cooperatives in C5. The dispersion in $\mathrm{C} 4$ is greater, i.e. although there is an elevated concentration of low leverages, there is, when compared to $\mathrm{C} 5$, higher participation of cooperatives with superior leverage. The higher level of leverage of C3 compared to C2 can also be associated with the larger size of the institutions in the group in terms of number of members.

In the next step, we analyzed the financial performance and technical efficiency of cooperatives based on the estimates of a SF model. The dependent variable was the log of the net loans (credit operations - loss provision). The determinants of the production function were: $\log$ of the number of members, a proxy for the cooperative size; log of the number of employees, a proxy for labor; a log of changes in the cooperative's average equity in the period (average equity + lowest average value +1 ), thus considering cooperatives with negative equity, which represents a proxy for the cooperative's capital.

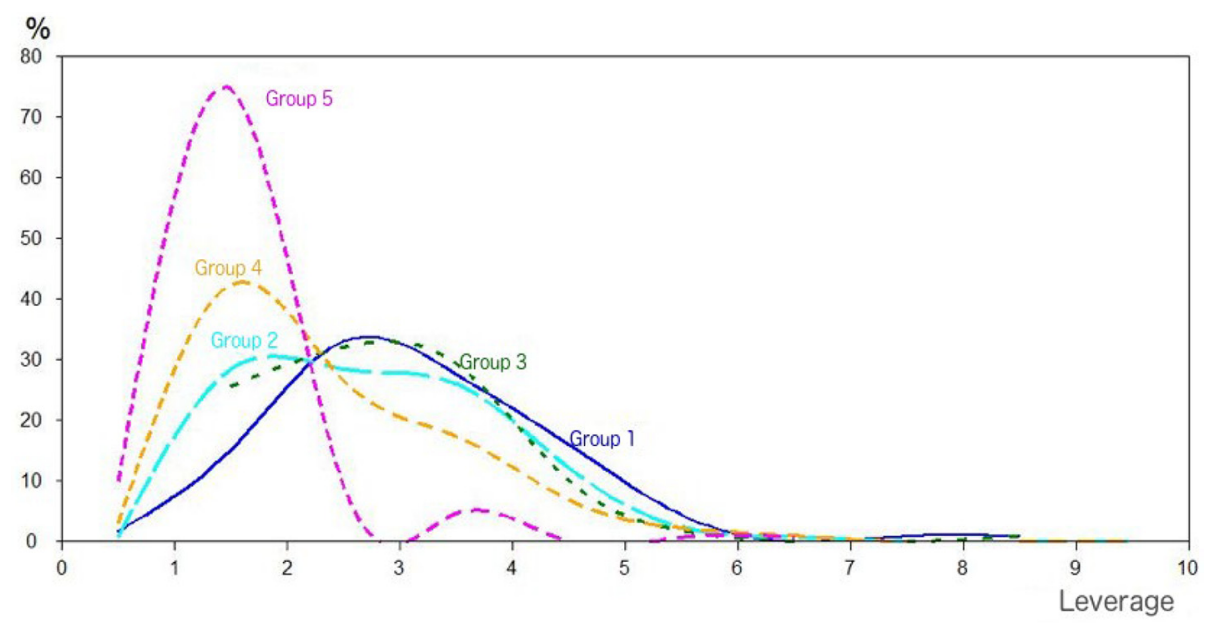

Figure 2. Frequency distribution for leverage ratios according to the cooperative Source: Research data 
RAUSP

55,3

\section{8}

The frontier model assumes that the inefficiency component $\left(u_{i}\right)$ only presents positive values, given that inefficiency represents a loss in credit operations with the situation of total efficiency determined by the size, amount of labor and capital of the cooperative. Also, the inefficiency component was considered to be dependent on: region, represented by four binary variables to define five regions (the South used as the reference); and governance group: represented by four binary variables to define the five groups of governance (C5 used as the reference).

Table 2 presents the estimates for the SF model. The results highlight that, holding other factors constant, the credit operations tend to grow more than proportionally to the cooperative's equity, showing average growth in operations of $1.1 \%$ for each $1 \%$ growth in equity.

The number of employees is also an important determinant of credit operations. The operations tend to increase by $0.5 \%$ for each $1 \%$ increase in the number of employees. Undoubtedly, cooperatives register a higher number of employees when they increase in size. However, this happens without detriment to economies of scale, since larger cooperatives have more employees, but at proportionally diminishing rates. The estimate associated with the number of members was insignificant in the frontier model; to some extent, due to the strong collinearity with the cooperative's equity, another explanatory variable adopted in the model.

Regarding the decomposition of the residuals $\left(\hat{e}_{i}=\hat{v}_{i}-\hat{u}_{i}\right)$, the significant estimate for $\gamma$ indicates that the variability related to inefficiency $\left(\sigma_{u}^{2}\right)$ plays an important role in the total variability of the errors $\left(\sigma_{v}^{2}+\sigma_{u}^{2}\right)$. In other words, the variability of the errors is not

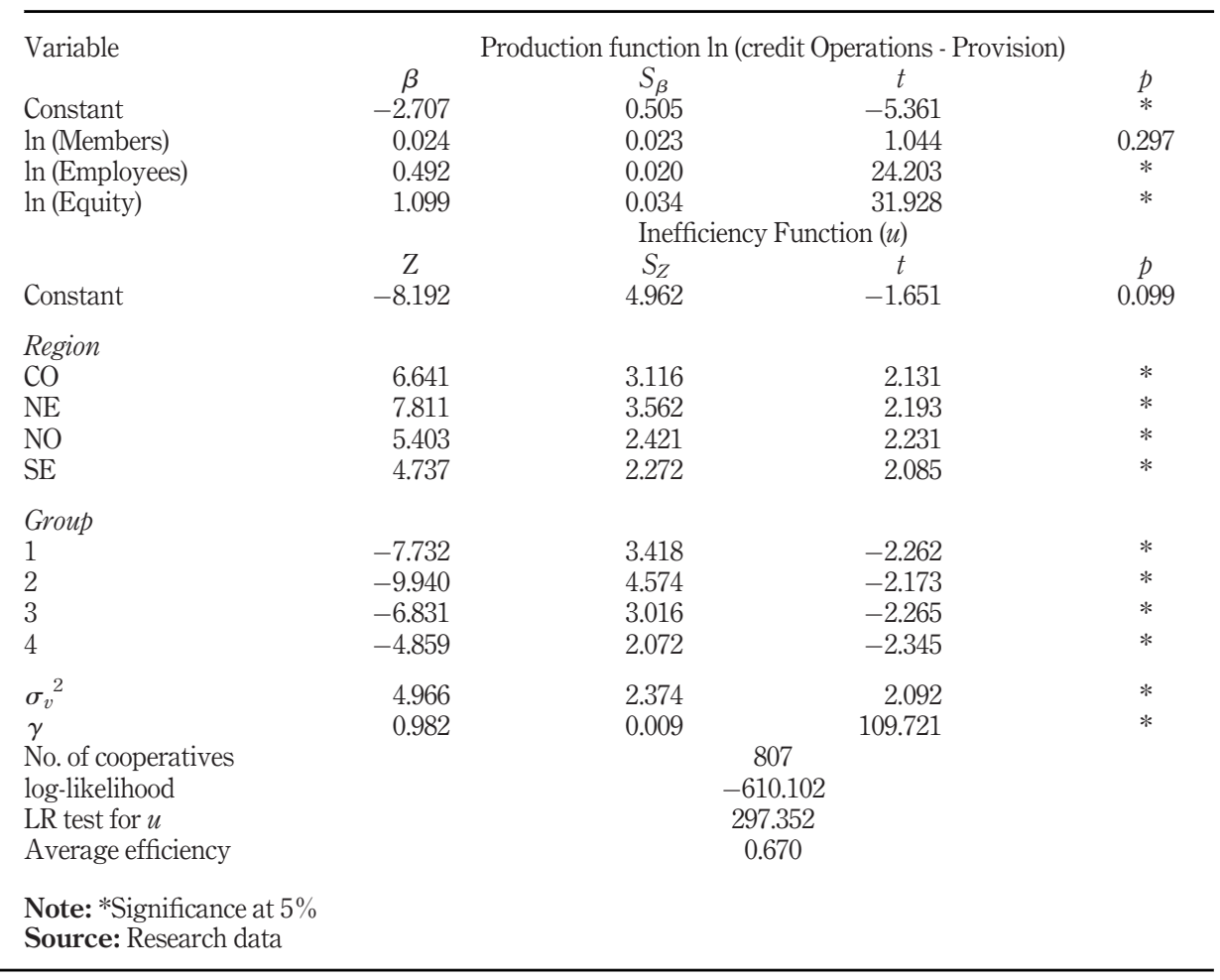

Table 2.

Maximum likelihood estimation for coefficients of the stochastic frontier model 
only a result of random shocks of the production function but also the inefficiency components of the model.

The average efficiency of the cooperatives $(\overline{T E})$ was nearly $67 \%$. The estimates also suggested an evident growth in efficiency related to good governance. The cooperatives of the first four groups present substantially superior levels of efficiency compared to the last and most precarious governance group. Efficiency is greater, above all, for the cooperatives in Groups 1 and 2. In terms of the geographic location, the cooperatives in the Southern region tend to present higher levels of efficiency, followed by the cooperatives in the Southeast. The most inefficient are those in the Northeast and Central-West.

\section{Discussion and conclusions}

There are a number of empirical challenges related to this area of study, particularly those related to the evaluation of credit union performance and to the definition and selection of variables to characterize cooperative governance. The first challenge is related to identifying characteristics relevant to defining good governance practices regarding representativeness and participation, leadership and management and supervision. The literature on cooperative governance is still limited, hampering any strategy to define a criterium based on pre-established or theoretical assumptions. In this respect, we used MCA to identify the most relevant dimensions to explain the differences in governance between the credit unions. MCA also opened up the possibility to extend this research, in demonstrating the items in the questionnaires that stood out in terms of evaluating governance in credit unions, in detriment to other items that did not enable the differentiation of institutions according to the objectives of this study.

Furthermore, the use of both multiple correspondence and cluster analyses allowed us to identify relatively homogeneous patterns of governance. We identified five groups of cooperatives that significantly differed in the dimensions of representativeness and participation, leadership and management and supervision. Cooperatives in Groups 1 and 3 presented the best results for representativeness and participation, a dimension that is associated with the mechanisms that stimulate the active participation of members. Prior studies have already suggested that membership participation is an important dimension to explain the financial performance and good governance practices of credit unions (Jones \& Kalmi, 2015; McKillop \& Wilson, 2015). Cooperatives in Groups 1 and 2 presented the best results for leadership, management and supervision. These dimensions are associated with the effectiveness of the advisory board and with mechanisms of remuneration, planning and adequateness of internal audit structures and other forms of supervision of administrative actions (monitoring function). In particular, prior studies have highlighted the importance of the monitoring function in corporate governance, as it is responsible for protecting members' interests against potential opportunism from managers (Guerrero et al., 2017).

The groups of corporate governance obtained in our analyses were largely associated with important socioeconomic indicators. For example, the groups of cooperatives with higher levels of governance prevailed in regions more familiar with rules and culture of cooperativism, particularly the Southern region. These groups of good governance also showed to have a larger number of members and to present better management practices, proxied by the ratio between the number of members and employees. The existence of higher levels of governance in larger credit unions may reflect the existence of economies of scale. Prior studies have also highlighted how size and management practices may affect the efficiency and longevity of credit unions (Carvalho et al., 2015; Martínez-Campillo et al., 2017). 
RAUSP

55,3

The estimates of the SF model highlighted significant and relatively consistent patterns in the relationship between good governance practices and the financial performance of credit unions. Our results indicated that the groups with higher levels of governance do operate more efficiently, based on the concept of a higher number of credit operations (net of loss provision) per cooperative. We can highlight the strikingly low efficiency of the group of cooperatives presenting the lowest levels of governance for all dimensions of analysis (participation, leadership, management and supervision), which is represented by 210 credit unions (18\% of the total). Not surprisingly, these cooperatives are also predominantly small in size (low economies of scale advantages), present the highest average number of members per employee (bad management practices) and are concentrated in the Southeast region, which is not historically known for credit unions. The results of the SF model also highlighted the importance of the total equity on financial performance. This result may reflect the fact that it is necessary to strive for constant growth to obtain and make viable the construction of efficient structures of management and governance and, as a result, reap future benefits.

In sum, this study made both empirical and theoretical contributions to the literature on governance of credit unions. The main empirical contribution was the ability to evaluate the relation of a complex and subjective concept of cooperative governance and the financial efficiency of credit unions. In this respect, the joint use of MCA and CA was able to provide groups of analysis that consistently differed in terms of socioeconomic characteristics and, more importantly, indicators of financial performance.

The main theoretical contribution was to prove that governance does affect financial efficiency, and differences are remarkably high between credit unions in Brazil. As financial efficiency is a key component for the survival in a highly competitive sector that tends toward concentration, our findings provided important information for policies oriented to the credit cooperativism in Brazil. Particularly, the importance of recommending better management and governance practices for credit unions, as these institutions play a key role in the financial system and the process of economic development as a whole. The research derived from this survey provided important insights into the monetary authority (BACEN) to improve resolutions regarding the corporate governance of credit unions in Brazil, including details on the incentive structure, management compensation policy and the management structure.

Finally, the study also presents a roadmap for future research. In particular, the need for additional studies to understand how poor governance may have influenced the survival rate of credit unions in the period of strong concentration since 2008. Further studies might also focus on the existence of reverse causation between financial performance and governance, i.e. if cooperatives with better performance are more likely to adopt better governance practices. This reverse causation may be more relevant in the post-2008 period of concentration, when governance may have become more important for survival in a competitive market.

\section{Notes}

1. The Brazilian Institute of Corporate Governance defines governance as: "the system in which organizations are driven, monitored and incentivized, involving the relationships between owners, the advisory board, board of directors and legislative bodies" (Instituto Brasileiro de Governança Corporativa, 2009).

2. Patin and McNiel (1991) produced a similar analysis, referring to the dominance of cooperative borrowers and lenders. 
3. It is worth mentioning that, under the Brazilian Law and Regulation applied over credit unions, it is not possible for these institutions to operate in financial activities with non-member customers.

4. Of the 1,199 cooperatives initially present in the sample, 15 presented 5 or more null answers and were therefore eliminated from our analysis.

5. Keeping in mind its central objective of providing members with the highest quality financial service, providing remuneration to executive management may be undesirable from a financeaccounting standpoint, and may be seen as a diversion from the purpose of the institution. Other mechanisms to measure performance can be used, such as increases in the number of members, in capital, in credit and/or deposit operations.

6. Operations with board of directors: commercial operations, credit concession or other economic activity of the entity with related party (individual or company) to a member of statutory organs or executive management.

7. Small-sized institutions may not have the economic requirements to provide remuneration to administrative/fiscal advisors. However, in the sense of minimizing agency conflicts, it is desirable to construct an incentive system in relation to the development of the institution.

8. The financial data on average leverage were obtained from the financial data registered by the institutions in accounts 1.6.0.00.00-1 Credit operations and 6.1.0.00.00-1 Equity. Thus, Leverage $=$ Credit operations/Equity. It is interesting to note that the sum of credit operations used excludes the loan loss provisions, which incorporates the variable of quality of credit operations to this concept of leverage. Regarding provisions for credit operations, see Resolution CMN 2.682/99.

\section{References}

Aigner, D., Lovell, C. A. K., \& Schmidt, P. (1977). Formulation and estimation of stochastic frontier production function models. Journal of Econometrics, 6, 21-37, https://doi.org/10.1016/0304-4076 (77) $90052-5$

Almeida, M. A., Santos, J. F., Ferreira, L. F. M., \& Torres, F. J. (2010). Evolução da qualidade das práticas de governança corporativa: Um estudo das empresas Brasileiras de capital aberto não listadas em bolsa. Revista de Administração Contemporânea, 14, 807-924, https://doi.org/ 10.1590/S1415-65552010000500009

Banco Central do Brasil. (2009). Governancôa cooperativa: Diretrizes e mecanismos para fortalecimento da governança em cooperativas de crédito, In G. Ventura, (Ed.) Brasilia: Banco Central do Brasil.

Banco Central do Brasil. (2018). Panorama do sistema nacional de crédito cooperativo, Brasília: Banco Central do Brasil.

Barroso, M. G. (2009). Distribuição de resultados e desempenho de cooperativas de crédito: Estudo comparativo no estado de são paulo, São Paulo, Brazil: Universidade de São Paulo.

Battese, G. E., \& Coelli, T. J. (1995). A model for technical inefficiency effects in a stochastic frontier production function for panel data. Empirical Economics, 20, 325-332, https://doi.org/10.1007/ BF01205442

Bertucci, J. O., Bernardes, P., \& Brandão, M. M. (2006). Políticas e práticas de governança corporativa em empresas Brasileiras de capital aberto. Revista de Administração, 41, 183-196.

Bressan, V. G., Braga, M. J., \& Bressan, A. A. (2010a). Eficiência e economia de escala em cooperativas de crédito: Uma abordagem de fronteira estocástica de custo com dados em painel. Advances in Scientific and Applied Accounting, 3, 335-352, https://doi.org/10.14392/ASAA.2010030304

Bressan, V. G., Braga, M. J., Bressan, A. A., \& Resende Filho, M. A. (2010b). A proposal of accounting indicators applied to Brazilian credit unions. Revista Contabilidade e Controladoria, 2, 58-80, https://doi.org/10.5380/rcc.v2i3.19625 
RAUSP 55,3

Bressan, V. G. F., Braga, M. J., Bressan, A. A., \& Resende-Filho, M. D A. (2012). O seguro depósito induz ao risco moral nas cooperativas de crédito brasileiras? Um estudo com dados em painel. Revista Brasileira de Economia, 66, 167-185, https://doi.org/10.1590/S0034-71402012000200002

Carvalho, F. L. D., Diaz, M. D. M., Bialoskorski Neto, S., \& Kalatzis, A. E. G. (2015). Exit and failure of credit unions in Brazil: A risk analysis. Revista Contabilidade \& Finanças, 26, 70-84, https://doi. org/10.1590/1808-057x201411390

Coelli, T., Rao, D. S. P., \& Battese, G. E. (1998). An introduction to efficiency and productivity analysis, Boston, MA: Kluwer Academic Publishers.

Crivisqui, E. (1999). Presentación de los métodos de clasificación, European Union: Programme de Reserche et D' Ensignement en Statistique (Presta).

Cuadras, C. M. (1981). Métodos de análisis multivariante, Barcelona, Spain: EUNIBAR.

Da Silva, T. P., Leite, M., Guse, J. C., \& Gollo, V. (2017). Financial and economic performance of major Brazilian credit cooperatives. Contaduria y Administración, 62, 1442-1459, https://doi.org/ 10.1016/j.cya.2017.05.006

Ferreira, M. A. M., Gonçalves, R. M. L., \& Braga, M. J. (2007). Investigação do desempenho das cooperativas de crédito de Minas Gerais por meio da análise envoltória de dados (DEA). Economia Aplicada, 11, 425-445, https://doi.org/10.1590/S1413-80502007000300006

Greenacre, M. J. (1984). Theory and applications of correspondence analysis, London, Orlando: Academic Press.

Greenacre, M., \& Hastie, T. (1987). The geometric interpretation of correspondence analysis. Journal of the American Statistical Association, 82, 437-447, https://doi.org/10.1080/01621459.1987. 10478446

Guerrero, S., Lapalme, M.-È., Herrbach, O., \& Séguin, M. (2017). Board member monitoring behaviors in credit unions: The role of conscientiousness and identification with shareholders. Corporate Governance: An International Review, 25, 134-144, https://doi.org/10.1111/corg.12196

Hoffman, D. L., \& Franke, G. R. (1986). Correspondence analysis: Graphical representation of categorical data in marketing research. Journal of Marketing Research, 23, 213, https://doi.org/ $10.2307 / 3151480$

Instituto Brasileiro de Governança Corporativa. (2009). Código das melhores práticas de governança corporativa, São Paulo, Brazil: IBGC.

Jones, D., \& Kalmi, P. (2015). Membership and performance in Finnish financial cooperatives: A new view of cooperatives?. Review of Social Economy, 73, 283-309, https://doi.org/10.1080/ 00346764.2015 .1067753

Khiari, W., Karaa, A., \& Omri, A. (2007). Corporate governance efficiency: An indexing approach using the stochastic frontier analysis. Corporate Governance: The International Journal of Business in Society, 7, 148-161, https://doi.org/10.1108/14720700710739796

Krieg, J. M. (2003). Credit unions: Who is in control? Northwest Journal of Business and Economics, Retrieved from: http://faculty.wwu.edu/ kriegj/Econ.\%20Documents/Credit\%20Unions5b.pdf

McKillop, D. G., \& Wilson, J. O. S. (2015). Credit unions as cooperative institutions: Distinctiveness, performance and prospects. Social and Environmental Accountability Journal, 35, 96-112, https://doi.org/10.1080/0969160X.2015.1022195

Maia, S. C., de Benedicto, G. C., do Prado, J. W., Robb, D. A., de Almeida Bispo, O. N., \& de Brito, M. J. (2019). Mapping the literature on credit unions: A bibliometric investigation grounded in Scopus and web of science. Scientometrics, 120, 929-960, https://doi.org/10.1007/s11192-01903165-1

Martínez-Campillo, A., Fernández-Santos, Y., \& Sierra-Fernández, M. D P. (2017). Eficiencia técnica en las cooperativas de crédito españolas: Una aproximación al impacto de la crisis. Spanish Journal of Finance and Accounting/Revista Española de Financiación y Contabilidad, 46, 484-506, https://doi.org/10.1080/02102412.2017.1288951 
Meeusen, W., \& van Den Broeck, J. (1977). Efficiency estimation from Cobb-Douglas production functions with composed error. International Economic Review, 18, 435, https://doi.org/10.2307/ 2525757

Paiva, B. G. M., \& Santos, N. F. (2017). Um estudo do cooperativismo de crédito no Brasil. Revista Da Universidade Vale Do Rio Verde, 15, 596-619, https://doi.org/10.5892/ruvrd.v15i2.4277

Patin, R. P., \& Mcniel, D. W. (1991). Benefit imbalances among credit union member groups: evidence of borrower-dominated, saver-dominated and neutral behaviour?. Applied Economics, 23, 769-780, https://doi.org/10.1080/00036849108841034

Pinheiro, M. A. H. (2008). Cooperativas de Crédito - História da evolucôão normativa no Brasil, Brasília: BrBCBasília.

Silveira, A. D. M. D., Perobelli, F. F. C., \& Barros, L. A. B. D C. (2008). Governança corporativa e os determinantes da estrutura de capital: Evidências empíricas no Brasil. Revista de Administração Contemporânea, 12, 763-788, https://doi.org/10.1590/S1415-65552008000300008

Vilela, D. L., Nagano, M. S., \& Merlo, E. M. (2007). Aplicação da análise envoltória de dados em cooperativas de crédito rural. Revista de Administração Contemporânea, 11, 99-120, https://doi. org/10.1590/S1415-65552007000600006

\section{Corresponding author}

Alexandre Gori Maia can be contacted at: gori@unicamp.br

Associate Editor: Wesley Mendes-Da-Silva

For instructions on how to order reprints of this article, please visit our website: 